\title{
Clinical application of ventriculoperitoneal shunting in treating traumatic brain injury
}

\author{
FANPENG MENG ${ }^{1}$, HAIYUAN WU ${ }^{2}$ and SHUGUANG YANG ${ }^{1}$ \\ Departments of ${ }^{1}$ Neurosurgery and ${ }^{2}$ Pathology, Shanxian Central Hospital, Heze, Shandong 274300, P.R. China
}

Received October 22, 2018; Accepted June 19, 2019

DOI: $10.3892 /$ etm.2019.7860

\begin{abstract}
This study explored the clinical application of ventriculoperitoneal (VP) shunting in treating traumatic brain injury (TBI). A retrospective analysis was performed on 100 patients who had hydrocephalus due to TBI and were admitted to Shanxian Central Hospital from February 2012 to June 2016. Among these patients, 50 underwent VP shunting surgery and were assigned to the experimental group. The remaining 50 underwent lumboperitoneal (LP) shunting surgery and were assigned to the control group. Twenty days after surgery, all patients were evaluated for clinical outcomes, neurological deficit scores and complications. The results were compared between the two groups. Patients in the experimental group were further separated into three subgroups according to the severity of hydrocephalus, and clinical outcomes were compared among the subgroups. It was found that the effective rate in the experimental group was significantly higher than that in the control group, and the difference was statistically significant $(\mathrm{P}<0.05)$. The effective rate in the mild hydrocephalus subgroup was significantly higher than that in the severe hydrocephalus subgroup, with a statistically significant difference $(\mathrm{P}<0.05)$. The effective rate in the moderate hydrocephalus subgroup was significantly higher than that in the severe hydrocephalus subgroup, with a statistically significant difference $(\mathrm{P}<0.05)$. The incidence of complications in the control group was significantly higher than that in the experimental group, and the difference was statistically significant $(\mathrm{P}<0.05)$. The postoperative neurological deficit score in the experimental group was significantly lower than that in the control group, and the difference was statistically significant $(\mathrm{P}<0.05)$. In conclusion, patients with hydrocephalus due to TBI had better clinical outcome when treated with VP shunting than those treated with LP shunting.
\end{abstract}

Correspondence to: Dr Fanpeng Meng, Department of Neurosurgery, Shanxian Central Hospital, West of Huxibei Road, Heze, Shandong 274300, P.R. China

E-mail:ma55rb@163.com

Key words: ventriculoperitoneal shunting, traumatic brain injury, hydrocephalus, lumboperitoneal shunting
Moreover, a better outcome was observed when the patient had milder hydrocephalus. Therefore, the early diagnosis and timely treatment with VP shunting are of great importance for patients with hydrocephalus.

\section{Introduction}

Traumatic brain injury (TBI) is a leading cause of death and disability in young adults (1). The majority of TBI is due to a blow to the head resulting from sports-related concussion, being hit by falling objects, or traffic accidents (2). Mild brain injury may lead to temporary brain disorders (3), while severe brain injury may cause tissue tears, bruises and even death (4). TBI has also a mental impact (5). Statistical research has shown that in 2013, 2.8 million TBI-related emergency department visits, hospitalizations, and deaths occurred in the United States, including 2.5 million TBI-related emergency department visits, 282,000 TBI-related hospitalizations, and $\sim 56,000$ TBI-related deaths (6). Hydrocephalus is a commonly encountered secondary brain disorder to TBI (7), whose pathogenesis is very complicated. Hydrocephalus is characterized by abnormal flow and absorbance of cerebrospinal fluid (CSF), which leads to dilated ventricles (8). When hydrocephalus occurs, there is a massive accumulation of CSF within the brain (9), causing increased pressure inside the skull. As a result, a series of neurological symptoms may develop. A surgical procedure, called ventriculoperitoneal (VP) shunting, can be performed to improve the brain symptoms (10).

A VP shunt is a medical device that consists of an implantable one-way valve to relieve the pressure in the brain. The excessive CSF can be shunted from the ventricle to the abdominal cavity for absorption (11). A VP shunt is suitable for all patients with hydrocephalus of different causes (12). It has been reported that VP shunting can reduce hydrocephalus mortality and morbidity $(13,14)$. However, complications such as postoperative infection, shunt obstruction, excessive drainage, shunt migration, and subdural hemorrhage may occur (15). When treating TBI with VP shunting, the shunt which consists of a one-way valve can be used to treat hydrocephalus with either normal intracranial pressure or high intracranial pressure (16). As medical technologies are advancing, treatment techniques of hydrocephalus are also maturing. So far, VP shunting has become the most common treatment option in clinical practice (17). In the present study, we explored the clinical application of VP shunting in treating TBI. 


\section{Patients and methods}

Patients. In total, 100 patients who had hydrocephalus due to TBI and were admitted to Shanxian Central Hospital (Heze, China) from February 2012 to June 2016 were recruited to this study. The patients were separated into two groups according to the different treatment methods: 50 patients in the experimental group and 50 patients in the control group. Patients in the experimental group underwent VP shunting, while patients in the control group underwent lumboperitoneal (LP) shunting. There were 31 males and 19 females in the experimental group. Their ages were 20-60 years and their average age was $37.5 \pm 6.8$ years. In the control group, there were 28 males and 22 females. Their ages were $21-64$ years and their average age was $36.9 \pm 7.2$ years. Using the ventricular/biparietal (V/BP) ratio as a scale of assessing the severity of hydrocephalus, the patients in the experimental group were further separated into three subgroups: 18 in the mild hydrocephalus subgroup, 17 in the moderate hydrocephalus subgroup and 15 in the severe hydrocephalus subgroup. All enrolled subjects were diagnosed with hydrocephalus in the Shanxian Central Hospital. Patients who had the following conditions were excluded from the study: i) severe impairment in cognitive function or mental function; ii) cardiovascular diseases; iii) liver or kidney dysfunction; or iv) endocrine system disorders. The study was approved by the Ethics Committee of Shanxian Central Hospital and written informed consents were obtained by the patients and/or guardians.

Methods. All patients received a routine examination before surgery. The procedures were done under general anesthesia after the hydrocephalus lesion was localized. Patients in the experimental group underwent VP shunting surgery using a shunt system (programmable pressure shunt system) manufactured by Medtronic. An arc-shaped hole was made in the skull 4-5 $\mathrm{cm}$ behind the right auricle. The size of the hole depended on the size of the reservoir base. Dura mater was cut, and the front end of a ventricular catheter was passed into the anterior horn of the ventricle. The catheter was cut to suitable length and connected to a reservoir. The reservoir was placed into the hole in the skull and secured to the dura, followed by suture of the incision. The outlet of the reservoir was connected to the valve in a pump. The arrow on the pump chamber was adjusted to point to the direction in which the CSF was shunted. The second step was to create a subcutaneous tunnel to run the second catheter from the incision in the head to the upper abdominal region through the neck and the chest. A subcutaneous tunnel was created in three segments. Incisions were made at the posterior mastoid, below the clavicle, and on the right upper abdomen below the xiphoid process. Then, using a blunt metal as a guide, each segment of the subcutaneous tunnel was opened by deep subcutaneous separation of tissue. The third step was to install the abdominal catheter. The proximal end of the catheter was connected to the valve outlet. The distal end was passed through the subcutaneous tunnel to arrive at the right upper abdominal incision. The fourth step was to suture the peritoneum and abdominal wall layer-by-layer, following securing the catheter.

Patients in the control group underwent LP shunting surgery using a shunt system (programmable pressure shunt
Table I. Grading scale of hydrocephalus.

Classification

V/BP value

\begin{tabular}{lc}
\hline Mild & $0.26-0.40$ \\
Moderate & $0.41-0.60$ \\
Severe & $>0.60$ \\
\hline
\end{tabular}

V/BP, ventricular/biparietal.

system). Patients were placed in the left lateral position. The preoperative and postoperative cares were the same as those for patients in the experimental group. In order to prevent any infection, patients in both groups were given antibacterial drugs once after surgery.

\section{Indicators observed and assessment}

Grading scale for hydrocephalus (18). The V/BP ratio was used to grade the severity of hydrocephalus. The grading scale is listed in Table I.

Outcome assessment (19). The following standards were established for the outcome assessment. An excellent outcome was achieved, if the CT results were all within the normal range and the patient's motor function was totally recovered. A satisfactory outcome was achieved, if significant improvements were observed in clinical symptoms and the patient's motor function, as well as in the CT results. An unsatisfactory outcome was achieved, if the conditions were not improved at all or became worse. The total effective rate was calculated using the formula: Total effective rate $=$ (cases of excellent outcome + cases of satisfactory outcome)/total number of cases $\times 100 \%$.

Postoperative neurological deficit scoring (20). A neurological deficit scoring system was designed to assess the patient's language function, response and awareness. The total score was 40 points. The higher the score, the more severe the neurological deficit. A patient with a score $>25$ points was regarded to have neurological deficits; $1-15$ points indicated mild neurological deficit; $16-25$ points indicated moderate neurological deficit; $25-40$ points indicated severe neurological deficit.

Statistical analysis. All data acquired in this study were analyzed using the SPSS 19.0 statistical software (IBM Corp.). Count data were expressed as n (\%), and Chi-square test was used for their comparison. Measurement data were expressed as the mean \pm standard deviation. Paired t-test was used for the comparison of the data between the experimental and the control group, before and after surgery. Repeated measures ANOVA with Least Significant Difference post hoc test were used for multiple comparisons. $\mathrm{P}<0.05$ was considered to indicate a statistically significant difference.

\section{Results}

General clinical records. There were no significant differences in age, sex, body weight, time of injury, cause of injury, Glasgow Outcome Scale (GOS) score at admission, and 
Table II. General clinical records of the patients.

\begin{tabular}{|c|c|c|c|c|}
\hline Variable & Experimental group $(n=50)$ & Control group $(n=50)$ & t or $\chi^{2}$ & P-value \\
\hline \multicolumn{5}{|l|}{ Age (years) } \\
\hline$>30$ & 24 & 27 & \multirow[t]{2}{*}{0.360} & \multirow[t]{2}{*}{0.548} \\
\hline$\leq 30$ & 26 & 23 & & \\
\hline \multicolumn{5}{|l|}{ Sex } \\
\hline Male & 31 & 28 & \multirow[t]{2}{*}{0.372} & \multirow[t]{2}{*}{0.542} \\
\hline Female & 19 & 22 & & \\
\hline \multicolumn{5}{|l|}{ Body weight (kg) } \\
\hline$>50$ & 22 & 26 & \multirow[t]{2}{*}{0.641} & \multirow[t]{2}{*}{0.423} \\
\hline$\leq 50$ & 28 & 24 & & \\
\hline Time of injury (h) & $56.84 \pm 27.55$ & $58.24 \pm 30.45$ & 0.241 & 0.810 \\
\hline \multicolumn{5}{|l|}{ Cause of injury } \\
\hline Traffic accident & 15 & 13 & \multirow[t]{4}{*}{0.264} & \multirow[t]{4}{*}{0.967} \\
\hline Blow to the head & 16 & 17 & & \\
\hline Falling object & 10 & 10 & & \\
\hline Other & 9 & 10 & & \\
\hline GOS score at admission & $2.95 \pm 0.68$ & $3.12 \pm 0.75$ & 1.187 & 0.238 \\
\hline \multicolumn{5}{|l|}{ Severity of hydrocephalus } \\
\hline Severe & 18 & 20 & \multirow[t]{3}{*}{0.467} & \multirow[t]{3}{*}{0.792} \\
\hline Moderate & 17 & 18 & & \\
\hline Mild & 15 & 12 & & \\
\hline
\end{tabular}

GOS, Glasgow Outcome Scale.

severity of hydrocephalus between the two groups $(\mathrm{P}>0.05)$. This indicated that the baselines of patients in the two groups were comparable. The general clinical records of the patients are listed in Table II.

Outcome comparison between the two groups. As shown in Fig. 1, the effective rate in the experimental group (56.00\%) was significantly higher than that in the control group $(36.00 \%)$, and the difference was statistically significant $\left(\chi^{2}=6.341, \mathrm{P}<0.05\right)$. The unsatisfactory outcome rate in the experimental group was significantly lower than that in the control group $(\mathrm{P}<0.05)$.

Outcome comparison among the subgroups of the experimental group. As shown in Table III, the effective rates in the severe, the moderate and the mild hydrocephalus subgroups were $33.33,76.47$ and $94.44 \%$, respectively. The effective rate in the mild hydrocephalus subgroup was significantly higher than that in the severe hydrocephalus subgroup, and the difference was statistically significant $(\mathrm{P}<0.05)$. The effective rate in the moderate hydrocephalus subgroup was significantly higher than that in the severe hydrocephalus subgroup, and the difference was statistically significant $(\mathrm{P}<0.05)$ (Table III).

Incidence of complications in the two groups. Patients in the control group underwent LP shunting surgery. Among the 13 cases of complications that were observed in this group, there were 4 cases of postoperative infection, 2 cases of shunt

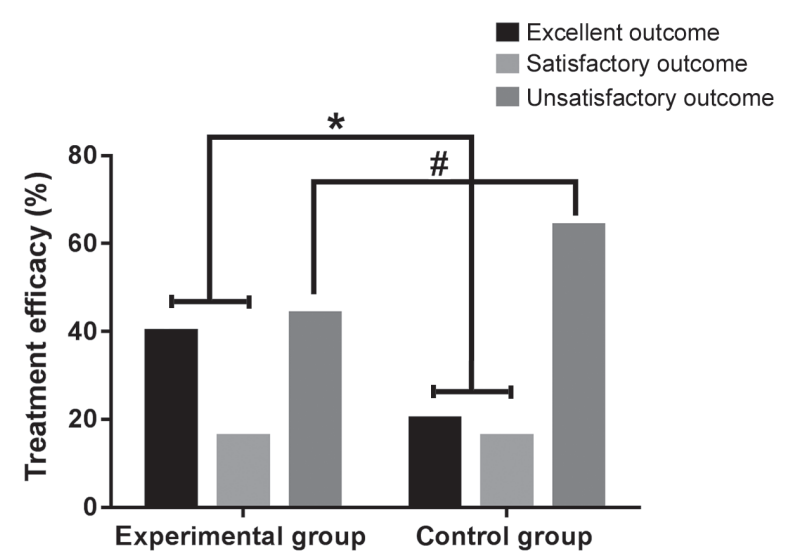

Figure 1. Outcome comparison between the two groups. The effective rate in the experimental group $(56.00 \%)$ was significantly higher than that in the control group (36.00\%), and the difference was statistically significant $\left(\chi^{2}=6.341,{ }^{*} \mathrm{P}<0.05\right)$. The unsatisfactory outcome rate in the experimental group was significantly lower than that in the control group $\left({ }^{\sharp} \mathrm{P}<0.05\right)$.

obstruction, 3 cases of excessive drainage, 2 cases of shunt migration, and 2 cases of subdural hemorrhage (Table IV). The incidence of complications was $26.00 \%$. Patients in the experimental group underwent VP shunting surgery. Among the 6 cases of complications that were observed in this group, there were 2 cases of postoperative infection, 1 case of shunt obstruction, 2 cases of excessive drainage, and 1 case of shunt migration. The incidence of complications was $12.00 \%$. Apparently, the incidence of complications in 
Table III. Outcome comparison among the subgroups within the experimental group [n (\%)].

\begin{tabular}{lcccc}
\hline Subgroup & Excellent & Satisfactory & Unsatisfactory & Total effective rate \\
\hline Mild $(\mathrm{n}=18)$ & $10(55.55)$ & $7(38.89)$ & $1(5.56)$ & $17(94.44)^{\mathrm{a}}$ \\
Moderate $(\mathrm{n}=17)$ & $8(47.06)$ & $5(29.41)$ & $4(23.53)$ & $13(76.47)^{\mathrm{a}}$ \\
Severe $(\mathrm{n}=15)$ & $1(6.67)$ & $4(26.66)$ & $10(66.67)$ & $5(33.33)$ \\
$\chi^{2}$ value & - & - & - & 15.06 \\
P-value & - & - & - & 0.001
\end{tabular}

${ }^{\mathrm{a}} \mathrm{P}<0.05$, compared with the severe subgroup.

Table IV. Incidence of complications in the two groups [n (\%)].

\begin{tabular}{lcl}
\hline Complication & $\begin{array}{c}\text { Control } \\
\text { group }(\mathrm{n}=50)\end{array}$ & $\begin{array}{c}\text { Experimental } \\
\text { group }(\mathrm{n}=50)\end{array}$ \\
\hline Postoperative infection & $4(8.00)$ & $2(4.00)$ \\
Shunt obstruction & $2(4.00)$ & $1(2.00)$ \\
Excessive drainage & $3(6.00)$ & $2(4.00)$ \\
Shunt migration & $2(4.00)$ & $1(2.00)$ \\
Subdural hemorrhage & $2(4.00)$ & $0(0)$ \\
Incidence & $13(26.00)$ & $6(12.00)^{\mathrm{a}}$ \\
\hline
\end{tabular}

${ }^{\mathrm{a}} \mathrm{P}<0.05$, compared with the control group.

Table V. Neurological deficit scores before and after surgery in the two groups.

\begin{tabular}{lcc}
\hline \multirow{2}{*}{ Group } & \multicolumn{2}{c}{ Neurological deficit score } \\
\cline { 2 - 3 } & Before surgery & After surgery \\
\hline Experimental group $(\mathrm{n}=50)$ & $28.63 \pm 8.90$ & $15.42 \pm 5.23$ \\
Control group (n=50) & $28.59 \pm 8.57$ & $22.54 \pm 6.84^{\mathrm{a}}$ \\
\hline
\end{tabular}

${ }^{\mathrm{a}} \mathrm{P}<0.05$, compared with the experimental group.

patients undergoing LP shunting surgery $(26.00 \%)$ was significantly higher than that in patients undergoing VP shunting surgery $(12.00 \%)$. The difference was statistically significant $\left(\chi^{2}=66.04, \mathrm{P}<0.05\right)$.

Neurological deficit scores before and after treatment in the two groups. The neurological deficit scores before and after treatment in the experimental group were $28.63 \pm 8.90$ and $15.42 \pm 5.23$, respectively, while the neurological deficit scores before and after treatment in the control group were $28.59 \pm 8.57$ and $22.54 \pm 6.84$, respectively (Table V). There was no significant difference in neurological deficit score between the two groups before surgery ( $\mathrm{t}=0.023, \mathrm{P}=0.982)$. However, the difference in neurological deficit score between the two groups was statistically significant after surgery $(\mathrm{t}=5.847, \mathrm{P}<0.05)$.

\section{Discussion}

TBI is a brain dysfunction caused by an external force, such as a violent blow to the head or concussion of the head and body (21). TBI has a certain impact on thinking and language abilities, as well as emotion (22). In severe cases, it may lead to permanent brain damage or death. Hydrocephalus is one of the common symptoms of TBI, which often leads to aggravation of the disease, affecting the patient's prognosis (23). It has been reported that hydrocephalus is a devastating disease (24). If not treated in time, hydrocephalus will not heal automatically. Therefore, surgical intervention is very important for the recovery of brain tissue.

In this study, 50 patients with hydrocephalus after TBI, who underwent VP shunting in Shanxian Central Hospital, were assigned to the experimental group. Another 50 patients with hydrocephalus after TBI, who underwent LP shunting, were assigned to the control group. Therapeutic outcomes were first compared between the experimental and the control group. The effective rate in the experimental group $(56.00 \%)$ was significantly higher than that in the control group (36.00\%), and the difference was statistically significant $(\mathrm{P}<0.05)$. Up to our knowledge, this is the first report in this regard. This result reveals that the therapeutic outcome using VP shunting is much better than that using LP shunting in treating TBI. Using the V/BP ratio as a scale of assessing the severity of hydrocephalus, the patients in the experimental group were further separated into three subgroups, i.e., the mild, the moderate and the severe hydrocephalus subgroups, and the clinical outcomes were compared among them. It turned out that the effective rates in the severe, the moderate and the mild hydrocephalus subgroups were $33.33,76.47$ and $94.44 \%$, respectively. The effective rate in the moderate hydrocephalus subgroup was significantly higher than that in the severe hydrocephalus subgroup, and the difference was statistically significant $(\mathrm{P}<0.05)$. The effective rate in the mild hydrocephalus subgroup was significantly higher than that in the severe hydrocephalus subgroup, and the difference was statistically significant $(\mathrm{P}<0.05)$. These findings suggest that VP shunting can better benefit patients with mild or moderate hydrocephalus than patients with severe hydrocephalus. The aforementioned results of the present study are consistent with a previous report (25). Also, as numerous complications have been reported after a ventricular shunting surgery (26), the incidence of complications was also assessed in this study. The incidence of 
complications following LP shunting surgery (26.00\%) was significantly higher than that following VP shunting surgery $(12.00 \%)$, and the difference was statistically significant $\left(\chi^{2}=66.04, \mathrm{P}<0.05\right)$. Due to the use of shunt cannulas in VP shunting surgery, the chance of a shunt obstruction and the incidence of complications were low. The infection rate in the LP group (8.00\%) was higher than VP group (4.00\%) in this experiment, which may be related to the indications of LP, the patient's personal condition, medical level, and surgical disadvantages. It has been reported that the ventricular shunting effect can be directly adjusted, leading to a low incidence of complications (15), which is in accordance with the results of this study. In the present study, preoperative and postoperative neurological deficit scores were obtained to assess the impact of ventricular shunting surgeries on patients' awareness, response, and language. The neurological deficit scores before and after treatment in the experimental group were $28.63 \pm 8.90$ and $15.42 \pm 5.23$, respectively, while the neurological deficit scores before and after treatment in the control group were $28.59 \pm 8.57$ and $22.54 \pm 6.84$, respectively. There was no significant difference in neurological deficit score between the two groups before surgery $(\mathrm{t}=0.023$, $\mathrm{P}=0.982$ ). However, the difference in neurological deficit score between the two groups was statistically significant after surgery $(\mathrm{t}=5.847, \mathrm{P}<0.05)$. These findings suggest that VP shunting surgery has less negative impact on postoperative neurological function, and this is consistent with a literature report (27). We followed up the patient's clinical efficacy to obtain satisfactory outcomes.

Due to the small sample size in this study, the results may contain certain biased findings. Therefore, more subjects will be enrolled for future studies.

In summary, VP shunting provides more benefits than LP shunting in patients with hydrocephalus after TBI, including low incidence of complications and better quality of life. Also, a better outcome is achieved when the patient has milder hydrocephalus. Therefore, patients with hydrocephalus should be early diagnosed and timely treated with VP shunting.

\section{Acknowledgements}

Not applicable.

\section{Funding}

No funding was received.

\section{Availability of data and materials}

The datasets used and/or analyzed during the current study are available from the corresponding author on reasonable request.

\section{Authors' contributions}

FM drafted the manuscript. FM and HW were responsible for the assessment of indicators. FM and SY performed the LP shunting surgery. SY assisted with statistical analysis. All authors read and approved the final manuscript.

\section{Ethics approval and consent to participate}

The study was approved by the Ethics Committee of Shanxian Central Hospital (Heze, China) and written informed consents were obtained by the patients and/or guardians.

\section{Patient consent for publication}

Not applicable.

\section{Competing interests}

The authors declare that they have no competing interests.

\section{References}

1. Hyder AA, Wunderlich CA, Puvanachandra P, Gururaj G and Kobusingye OC: The impact of traumatic brain injuries: A global perspective. NeuroRehabilitation 22: 341-353, 2007.

2. Ommaya AK and Gennarelli TA: Cerebral concussion and traumatic unconsciousness. Correlation of experimental and clinical observations of blunt head injuries. Brain 97: 633-654, 1974.

3. McCrea M, Iverson GL, McAllister TW, Hammeke TA, Powell MR, Barr WB and Kelly JP: An integrated review of recovery after mild traumatic brain injury (MTBI): Implications for clinical management. Clin Neuropsychol 23: 1368-1390, 2009.

4. Graham DI, Adams JH and Doyle D: Ischaemic brain damage in fatal non-missile head injuries. J Neurol Sci 39: 213-234, 1978.

5. Bryant RA, O'Donnell ML, Creamer M, McFarlane AC, Clark CR and Silove D: The psychiatric sequelae of traumatic injury. Am J Psychiatry 167: 312-320, 2010.

6. Taylor CA, Bell JM, Breiding MJ and Xu L: Traumatic brain injury-related emergency department visits, hospitalizations, and deaths - United States, 2007 and 2013. MMWR Surveill Summ 66: 1-16, 2017.

7. Ommaya AK, Goldsmith W and Thibault L: Biomechanics and neuropathology of adult and paediatric head injury. Br J Neurosurg 16: 220-242, 2002.

8. Zhang J, Williams MA and Rigamonti D: Genetics of human hydrocephalus. J Neurol 253: 1255-1266, 2006.

9. Bering EA Jr and Sato O: Hydrocephalus: Changes in formation and absorption of cerebrospinal fluid within the cerebral ventricles. J Neurosurg 20: 1050-1063, 1963.

10. Dixon GR, Friedman JA, Luetmer PH, Quast LM, McClelland RL, Petersen RC, Maher CO and Ebersold MJ: Use of cerebrospinal fluid flow rates measured by phase-contrast MR to predict outcome of ventriculoperitoneal shunting for idiopathic normal-pressure hydrocephalus. Mayo Clin Proc 77: 509-514, 2002.

11. Battal B, Kocaoglu M, Bulakbasi N, Husmen G, Tuba Sanal H and Tayfun C: Cerebrospinal fluid flow imaging by using phase-contrast MR technique. Br J Radiol 84: 758-765, 2011.

12. Schoenbaum SC, Gardner P and Shillito J: Infections of cerebrospinal fluid shunts: Epidemiology, clinical manifestations, and therapy. J Infect Dis 131: 543-552, 1975.

13. Reddy GK, Bollam P, Caldito G, Willis B, Guthikonda B and Nanda A: Ventriculoperitoneal shunt complications in hydrocephalus patients with intracranial tumors: An analysis of relevant risk factors. J Neurooncol 103: 333-342, 2011.

14. Zhang J, Qu C, Wang Z, Wang C, Ding X, Pan S and Ji Y: Improved ventriculoatrial shunt for cerebrospinal fluid diversion after multiple ventriculoperitoneal shunt failures. Surg Neurol 72 (Suppl 1): S29-S34, 2009.

15. Grosfeld JL, Cooney DR, Smith J and Campbell RL: Intraabdominal complications following ventriculoperitoneal shunt procedures. Pediatrics 54: 791-796, 1974.

16. Murtagh $\mathrm{F}$ and Lehman R: Peritoneal shunts in the management of hydrocephalus. JAMA 202: 1010-1014, 1967.

17. Limbrick DD Jr, Baird LC, Klimo P Jr, Riva-Cambrin J and Flannery AM; Pediatric Hydrocephalus Systematic Review and Evidence-Based Guidelines Task Force: Pediatric hydrocephalus: systematic literature review and evidence-based guidelines. Part 4: Cerebrospinal fluid shunt or endoscopic third ventriculostomy for the treatment of hydrocephalus in children. J Neurosurg Pediatr 14 (Suppl 1): 30-34, 2014. 
18. Hebb AO and Cusimano MD: Idiopathic normal pressure hydrocephalus: A systematic review of diagnosis and outcome. Neurosurgery 49: 1166-1186, 2001.

19. Constine LS, Konski A, Ekholm S, McDonald S and Rubin P: Adverse effects of brain irradiation correlated with MR and CT imaging. Int J Radiat Oncol Biol Phys 15: 319-330, 1988.

20. Cao M and Wu JI: Camk2a-Cre-mediated conditional deletion of chromatin remodeler Brg1 causes perinatal hydrocephalus. Neurosci Lett 597: 71-76, 2015.

21. Walker WC and McDonald SD: Does neurologic examination during inpatient rehabilitation help predict global outcome after nonpenetrating traumatic brain injury? PM R 3: 6-12, 2011.

22. McDonald S and Flanagan S: Social perception deficits after traumatic brain injury: Interaction between emotion recognition, mentalizing ability, and social communication. Neuropsychology 18 : 572-579, 2004

23. Yang XF, Wen L, Shen F, Li G, Lou R, Liu WG and Zhan RY: Surgical complications secondary to decompressive craniectomy in patients with a head injury: A series of 108 consecutive cases. Acta Neurochir (Wien) 150: 1241-1248, 2008.
24. Rekate HL: A contemporary definition and classification of hydrocephalus. Semin Pediatr Neurol 16: 9-15, 2009.

25. Chumas PD, Armstrong DC, Drake JM, Kulkarni AV,Hoffman HJ, Humphreys RP, Rutka JT and Hendrick EB: Tonsillar herniation: The rule rather than the exception after lumboperitoneal shunting in the pediatric population. J Neurosurg 78: 568-573, 1993.

26. Chung JJ, Yu JS, Kim JH, Nam SJ and Kim MJ: Intraabdominal complications secondary to ventriculoperitoneal shunts: CT findings and review of the literature. AJR Am J Roentgenol 193: 1311-1317, 2009.

27. Pudenz RH and Foltz EL: Hydrocephalus: Overdrainage by ventricular shunts. A review and recommendations. Surg Neurol 35: 200-212, 1991.

(i) (3) This work is licensed under a Creative Commons Attribution-NonCommercial-NoDerivatives 4.0 International (CC BY-NC-ND 4.0) License. 